\title{
Yayla alanlarındaki yapılaşma değişiminin incelenmesi: Gümüşhane örneği
}

\author{
Examination of change in summer pasture areas: Gümüşhane case
}

Fatih DÖNER*1,a

${ }^{1}$ Gümüşhane Üniversitesi, Mühendislik ve Doğa Bilimleri Fakültesi, Harita Mühendisliği Bölümü, 29100, Gümüşhane

\author{
• Geliş tarihi / Received: 05.06.2020 • Düzeltilerek geliş tarihi / Received in revised form: 02.04.2021 • Kabul tarihi / Accepted: 14.04 .2021
}

\begin{abstract}
$\ddot{O} \mathbf{z}$
Bu çalışmada yayla alanlarındaki yapılaşma değişimi Coğrafi Bilgi Sistemleri (CBS) ve Uzaktan Algılama (UA) verilerinin birlikte kullanımıyla incelenmektedir. Gümüşhane ilinde bulunan Ernek, Güvende, Kadırga ve Kazıkbeli isimli dört yayla alanında 2013 ile 2018 yılları arasındaki değişim incelenmiştir. İncelenen yayla alanlarında 2013 ile 2018 yılları arasında yapı sayısının \%21.48, yol ağının \%6.94 artığı belirlenmiştir. Bu artışın temel sebeplerinin yayla alanlarına yönelik turizm faaliyetleri ve İmar Barışı düzenlemesinin olduğu değerlendirilmektedir. Yayla alanlarının sürdürülebilir kullanımı için koruma-kullanma dengesini gözeten bir arazi kullanım politikasına ve daha etkin bir denetim mekanizmasına ihtiyaç vardır. CBS ve UA verileri yayla alanlarındaki değişimin izlenerek kontrol edilmesi çalışmalarına destek sağlamak için kullanılabilir.
\end{abstract}

Anahtar kelimeler: Coğrafi bilgi sistemleri, Turizm, Uzaktan algılama, Yayla

\begin{abstract}
In this study, the change of built areas in summer pasture is analyzed by using Geographic Information Systems (GIS) and Remote Sensing (RS) data together. The change between 2013 and 2018 was examined in the four summer pasture areas named Ernek, Güvende, Kadırga and Kazlkbeli in Gümüşhane. Between 2013 and 2018, the number of buildings increased by $21.48 \%$ and the road network increased by $6.94 \%$ in the study area. It is considered that the main reasons for this increase are tourism activities for summer pasture areas and Development Peace regulation. For the sustainable use of the summer pasture areas, there is a need for a land use policy and a more effective control mechanism that considers the conservation-use balance. GIS and RS data can be used to support studies to monitor and control changes in summer pasture areas.
\end{abstract}

Keywords: Geographic information systems, Tourism, Remote sensing, Summer pasture

*a Fatih DÖNER; fatihdoner@gumushane.edu.tr, Tel: (0456) 23317 65, orcid.org/0000-0002-3620-5687 


\section{Giriş}

Arazi bütün yaşamsal ve ekonomik faaliyetlerin temelini oluşturmaktadır. Tarım, ormancılık, ulaşım ve barınma gibi faaliyetler için arazi kullanılmakta ve bu faaliyetlere bağlı olarak zamanla arazi kullanımında değişiklikler olmaktadır. Arazi kullanımındaki bu değişiklikler iklim değişikliği, biyolojik çeşitliliğin azalması, hava, su ve toprak kirlenmesi gibi pek çok çevre sorununa yol açabilmektedir (EEA, 2010). Tarım devrimi döneminde insanların barınma ve beslenme ihtiyaçlarının karşılanabilmesi için bir varlık kaynağı olarak kabul edilen arazi, zamanla ulaşım olanaklarının gelişmesiyle önce alınıp satılabilen ticari bir varlık olarak kabul edilmiş, İkinci Dünya Savaşı sonrası dönemde kıt bir kaynak olarak değerlendirilmiş ve 1980'li yıllardan itibaren 'Sürdürülebilir Kalkınma' kavramıyla birlikte toplumsal bir kit kaynak olarak ele alınmıştır (Ting ve Williamson, 1999).

Türkiye'nin önemli arazi kaynaklarından olan yaylalar, Mera Kanunu'nda çiftçilerin hayvanları ile birlikte yaz mevsimini geçirmeleri, hayvanlarını otlatmaları ve otundan yararlanmaları için tahsis edilen araziler olarak tarif edilmektedir (RG, 1998). Yaylalar Türkiye'nin birçok bölgesinde bulunmakta ve yem ihtiyacının karşılandığı alanlar olarak ülke hayvancılığına önemli katkı sunmaktadır. Bununla birlikte, geçmişte hayvancılık faaliyetleri için kullanılan yaylalar zaman içerisinde hayvancılıkla uğraşan nüfusun azalması ve göç gibi nedenlerle hayvancılık yerine tatil ve turizm amaçlı kullanılmaya başlanmıştır. Bunun sonucunda da yaylardaki arazi kullanımında önemli değişiklikler meydana gelmiştir (Yonca, 2014; Türk, 2019).

Şakar ve Kurucuca (2019)'da Türkiye'de yaylalarla ilgili olarak yapılmış lisansüstü çalışmaların bibliyometrik analizi yapılmıştır. Buna göre, doğrudan yaylarla ilgili olarak yaklaşık 150 lisansüstü (yüksek lisans ve doktora) çalışma bulunmaktadır. $\mathrm{Bu}$ çalışmaların 4'te 3'ünü Biyoloji, Coğrafya, Jeoloji, Mimarlık, Orman Mühendisliği ve Ziraat alanlarında yapılmış tezler oluşturmaktadır. Yaylalardaki değişimin belirlenmesine yönelik çalışmalar ise oldukça sinırlıdır. Somuncu vd., (2010)'da 1973 ile 2004 yılları arasında Gümüşhane ili Kazıkbeli ve Alistire yaylarındaki arazi kullanımı ve işlev değişimi değerlendirilmiştir. Akar (2014)'te Trabzon ili Akçaabat ilçesindeki yayla ve mera alanlarının 1973 ile 2013 yılları arasındaki değişimi hava fotoğrafları ve uydu görüntüleri kullanılarak tespit edilmiştir. Ceylan (2014)'te Gümüşhane ilinde bulunan Bezendi, Eylence, Gürpınar ve Karışık yayla alanlarının 1982-2011 yılları arasındaki değişimi hava fotoğrafları ve uydu görüntüleri kullanılarak izlenmiştir. Cin (2019)'da Giresun ilinde seçilen üç yayla alanında İmar Barışı düzenlemesinin etkileri uydu görüntüleri ile belirlenmiştir. Başer (2019)'da Giresun ilinde seçilen üç yayla alanında arazi kullanım değişimi Coğrafi Bilgi Sistemleri ile analiz edilmiştir.

Zaman içerisinde yaylacılık yapan nüfusun azalması, yaylaları ilgilendiren yasal düzenlemeler, denetim eksiklikleri ve yaylalara yönelik turizm politikaları gibi nedenler yaylalardaki arazi kullanımını değiştirerek yapılaşmanın ve yol ağının artmasına sebep olmuştur. $\mathrm{Bu}$ nedenle, yayla alanlarındaki değişimin belirlenmesine yönelik güncel çalışmalara ihtiyaç vardır. Gümüşhane, toplam 440 yayla ile Doğu Karadeniz Bölgesi'nde en çok yaylaya sahip olan ildir (Gümüşhane Valiliği, 2017). Yayla alanlarındaki değişime etki edebilecek güncel gelişmelerden biri, 2013 yılında başlatılan Gümüşhane'nin de aralarında bulunduğu Doğu Karadeniz Bölgesi'ndeki sekiz ilin yaylarını birbirine bağlayarak bir yayla koridoru oluşturmayı amaçlayan Yeşil Yol Turizm Projesi'dir. Yayla alanlarına etki edebilecek diğer gelişme ise 2018 yılında yürürlüğe giren ve İmar Barışı olarak duyurulan 7143 sayılı yasadır. Bu çalışmada, Gümüşhane ili yayla alanlarında 2013 ile 2018 yılları arasındaki yapılaşma değişiminin Coğrafi Bilgi Sistemleri (CBS) ve Uzaktan Algilama (UA) verileri ile belirlenmesi amaçlanmaktadır. Çalışmanın ikinci bölümünde turizm faaliyetleri ve yasal düzenlemeler ele alınmaktadır. Üçüncü bölümde, kullanılan materyal ve yöntem tanıtılmaktadır. Çalışmanın bulguları dördüncü bölümde sunulmaktadır. Çalışma sonuç bölümüyle sona ermektedir.

\section{Turizm faaliyetleri ve yasal düzenlemelerinin yaylalara etkisi}

$\mathrm{Bu}$ bölümde turizm faaliyetlerinin ve izinsiz yapıların yasallaştırılmasına yönelik yasal düzenlemelerin yaylalara etkisi ele alınmaktadır.

\subsection{Turizm faaliyetleri}

Türkiye'de yaylaların turizm amaçlı kullanımı ilk kez 1990'lı yılların başlarında gündeme gelmiştir. Turizmi Teşvik Kanunu esas alınarak, Turizm Bakanlığı'nca (TB) 1990 yılında Karadeniz Bölgesi'nde 12 yayla, turizm merkezi ilan edilerek bu yaylalar için çevre düzeni planları hazırlanmıştır (RG, 1990; Bay, 2014). 2019 yıll itibariyle Turizmi 
Teşvik Kanunu kapsamında yayla turizm merkezi ilan edilen yayla sayısı 21 'e ulaşmış olup bunların 18 tanesi Karadeniz Bölgesi'ndeki illerde yer almaktadır (Şekil 1, TB, 2020). Bununla birlikte, yaylaların turizm ve rekreasyon amaçlı değerlendirilmesi konusunun Türkiye'nin uzun vadeli turizm politikalarına yansıması 2000'li yılların sonlarında gerçekleşmiştir. TB tarafından 2007 y1lında hazırlanan 'Türkiye 2023 Turizm Stratejisi Eylem Planı'nda 2013 y1lı sonuna kadar Karadeniz Bölgesi'nde Samsun ilinden Artvin iline kadar uzanan bölge bir 'yayla koridoru' (Şekil 1) olarak tanımlanarak bu bölgede yayla turizminin geliştirileceği ve buna yönelik altyapının oluşturulacağı ifade edilmiştir. Eylem planında yer alan bu politikanın uygulamaları olarak Karadeniz Bölgesinde 'yayla turizmi' temasıyla yeni taşıt yollarının açılması, ulaşım altyapısının tamamlanması ve güzergâh haritalarının oluşturulması gibi hedefler belirlenmiştir (RG, 2007).

2007 yılında yayınlanan eylem planında belirtilen hedefleri hayata geçirmek için, Turizm Master Planı kapsamında, 2013 yılında Kalkınma Bakanlığı, Doğu Karadeniz Bölge Kalkınma İdaresi Başkanlığı (DOKAP) tarafından yürütülecek 'Yeşil Yol Projesi'ni başlatmıştır. Bu proje Karadeniz Bölgesi'ndeki sekiz ilin (Artvin, Bayburt, Giresun, Gümüşhane, Ordu, Rize, Samsun, Trabzon) önemli yaylalarını ve turizm merkezlerini birbirine bağlamayı amaçlayan doğa ile bütünleşik bir turizm projesi olarak tarif edilmiştir. DOKAP eylem planı kapsamında 2023 yılına kadar tamamlanması hedeflenen Yeşil Yol Projesi toplamda $4000 \mathrm{~km}$ 'lik bir yol ağından oluşmaktadır. 2019 yılı itibariyle 1300 km'lik kısımda DOKAP tarafindan yol iyileştirme çalışmaları tamamlanmıştır. Yol iyileştirme çalışmaları kapsamında $285 \mathrm{~km}$ yol asfalt kaplama yapilmış, $177 \mathrm{~km}$ yol stabilize kaplama yapılmış, $99 \mathrm{~km}$ yol beton kaplama yapılmış, $18 \mathrm{~km}$ yol parke kaplama yapılmış, geri kalan kısımda ise bakım-onarım çalışmaları gerçekleştirilmiştir. Kalan 2700 km'lik bölümün 2023 y1lına kadar Karayolları Genel Müdürlüğü ve DOKAP tarafindan birlikte tamamlanması planlanmaktadır (DOKAP, 2020). Projenin temel amaçlarından biri standardı artırılacak yol ağıyla yaylalarda yılın belirli aylarına sıkışan turizm talebinin daha geniş bir takvime yayılmasıdır. Bunun yanında, doğubatı doğrultusunda bir yol güzergahıyla birbirine bağlanacak yaylaların bölgeye gelen turistlere daha çok alternatif sunması hedeflenmektedir. Turistler yanında, yaylacılık yapan yerel halkın da ulaşım olanaklarının kolaylaştırılması ve gelir düzeyinin artırılması Yeşil Yol Projesinin hedefleri arasindadir.

\subsection{Yasal düzenlemeler}

Çevre ve Şehircilik Bakanlığı (ÇŞB) verilerine göre Türkiye'de bulunan 26.4 milyon yapının (bağımsız birim) yaklaşık \%50'si mevzuata aykırı yapı kapsamındadır (ÇŞB, 2018). Özellikle kentlerin gelişme bölgelerinde yoğunlaşan bu yapılar kentsel alanların gelişimini engellerken tarım, mera ve orman alanlarına da zarar vermektedirler. Bugüne kadar hazırlanan kalkınma planları incelendiğinde Türkiye'de mevzuata aykırı yapılaşmanın sürekli olarak artmasının temel nedenleri arasında kadastro çalışmalarının zamanında tamamlanmamış olmasının, kadastro verilerindeki içerik probleminin ve mera kanununun zamanında çıkarılamamış olmasının s1klıkla ifade edildiği görülmektedir (RG, 1989; RG, 1995).

Kalkınma planlarında da siklıkla yer bulan kayıt dışı yapılaşma problemine çözüm bulmak amacıyla Türkiye'de yasallaştırma politikalarının günümüze kadar benimsendiği görülmektedir (Cengiz vd., 2019; Arslanoğlu, 2019; Gürbüztürk, 2017). Türkiye'de 1948 ile 2018 yılları arasında yürürlüğe giren toplam 16 yasanın kentlerde ve kırsal alanlardaki araziler üzerinde bulunan mevzuata aykırı yapıları kayıt altına almak için hükümler içerdiği anlaşılmaktadır. Bu yasalar dışında kayıt dışı yapılara altyap1 hizmeti götürülmesini sağlayan ve yasallaştırmada süre uzatımına imkân veren 7 ayrı yasa daha bulunmaktadır. $\mathrm{Bu}$ yasalardan sonuncusu olan ve 2018 yilında yürürlüğe giren 7143 sayılı yasa hem önceki yasalardan daha geniş kapsamlı olması hem de bu makalenin konusunu oluşturan yaylalar üzerinde bir etki yapması bakımından önemlidir.

08.05.2018 tarihinde yürürlüğe giren 7143 sayılı yasa 'İmar Barışı' olarak duyurulmuştur. Bu yasa 31.12.2017 tarihinden önce yapılmış kentsel ve kırsal arazilerdeki tüm izinsiz yapıları kapsamaktadır. İzinsiz yapı sahiplerinin başvurusu sonucunda hazırlanacak Yapı Kayıt Belgesi (YKB) ile tapu kütügüne tescil işlemleri gerçekleştirilmek olanaklı hale gelmiştir. Ayrıca, hazine arazileri üzerinde bulunan izinsiz yapılar da YKB almak için başvuru hakkına kavuşmuştur. YKB, izinsiz yap1 sahiplerine yapıları için daha önce alınmış yıkım kararlarını durdurma, para cezalarının iptali, elektrik, doğalgaz gibi altyap1 hizmetlerinden yararlanma ve tapuya tescil yoluyla mülkiyet güvencesi imkânları sağlamaktadır. YKB almak için başlangıçta 31.10.2018 olarak belirlenen son 
başvuru tarihi iki kez uzatılarak 15.06.2019 olarak güncellenmiştir. YKB almak için ödenmesi gereken bedelin son ödeme tarihi ise 31.12.2019 olmuştur. YKB başvuruları internet üzerinden eDevlet uygulamasıyla izinsiz yapı sahibinin beyanı esas alınarak toplanmıştır. Başvuru sırasında hesaplanan YKB bedelinin bankaya yatırılmas1 ardından YKB hazırlanarak hak sahiplerine verilmiştir. İmar Barışı olarak duyurulan bu yasanın temel amacı yasa dışı kullanımları yasallaştırmak olarak tarif edilmiştir. Bunun yanında, kentsel dönüşüm projeleri için ihtiyaç duyulan ekonomik kaynağın üretilmesi de yasanın temel hedeflerinden biri olmuştur.

Yasanın yürürlüğe girmesinin ardından özellikle Doğu Karadeniz Bölgesi'ndeki yayla ve mera alanlarında hızlı bir yapılaşma yaşanmıştır. 31.12.2017 tarihinden sonra yapılan yapılar daha önce yapılmış gibi gösterilerek YKB başvuruları gerçekleştirilmiştir. Bunun üzerine, Tarım ve Orman Bakanlığı'nca valiliklere bir uyarı gönderilerek bu yapıların Mera Kanunu'na göre işgal kapsamında değerlendirilmesi gerektiği belirtilmiştir. $\mathrm{Bu}$ uyarının ardından, ÇŞB ekiplerince tespit edilen yapılar için YKB iptal ve yıkım süreci başlatılmıştır. Trabzon ili sınırları içerisindeki yaylalarda yasaya aykırı şekilde inşa edilmiş 160 bina ve Gümüşhane ili sınırları içindeki yaylalarda 91 bina öncelikli olarak yıkılmıştır. ÇŞB yaptığı açıklamada YKB almak için yaklaşık 7.4 milyon yapının (bağımsız birim) başvuru yaptı̆g 1 , bu yapılardan 20158 tanesinin yasaya aykırılık nedeniyle YKB'nin iptal edildiği duyurulmuştur. ÇŞB bu konudaki denetimlerin devam ettiğini, tespit edilecek usulsüz başvurular için yasal işlem başlatılacağını duyurmuştur (AA, 2020).

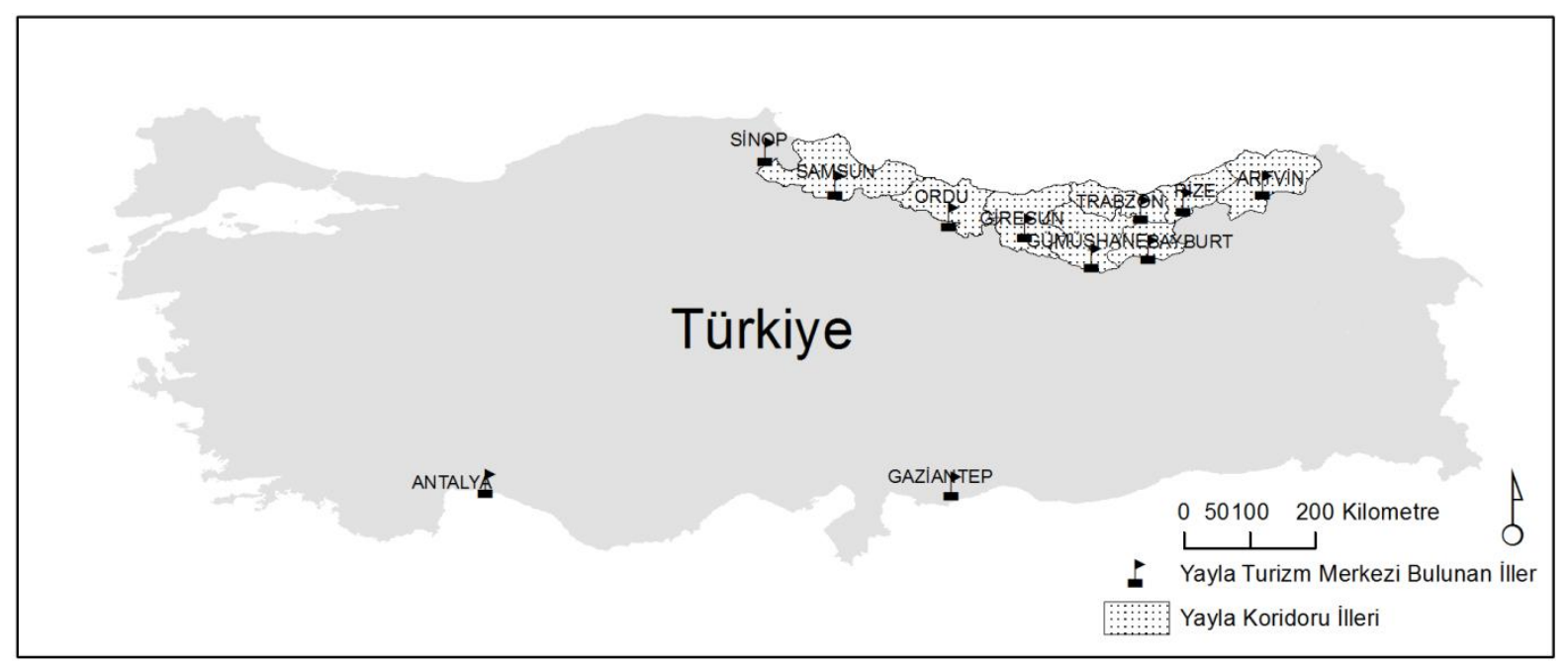

Şekil 1. Türkiye'de Turizm Bakanlığı'nca turizm merkezi ilan edilen yaylanın bulunduğu iller ve 'Yayla Koridoru' illeri

\section{Materyal ve yöntem}

$\mathrm{Bu}$ çalışmada yayla alanlarındaki değişimi belirlemek için CBS ve UA verileri kullanılmaktadır. Şekil 2'de çalışmada takip edilen işlem adımları gösterilmektedir. Çalışma alanı olarak Gümüşhane ili Ernek, Güvende, Kadırga ve Kazıkbeli yayla alanları belirlenmiştir. Bu yayla alanlarının belirlenmesinin nedeni dört yaylanın da geleneksel yaylacılık faaliyetleri yapılan yaylalar olması yanında İl Kültür ve Turizm Müdürlüğü tarafindan hazırlanan rehberde yer alan yaylalar olmasıdır. Turizm potansiyelinin yüksek olduğu bu yaylalar her yıl yaz aylarında Gümüşhane ve çevre illerden çok sayıda kişi tarafından ziyaret edilmektedir. Ayrıca, bu yayla alanlarına ulaşımın sağlanması için yol yapım ve iyileştirme çalışmaları 2013 yılı sonrası Yeşil Yol Projesi kapsamında tamamlanmıştır. Çalışma alanı Şekil 3'de Gümüşhane ilindeki başlıca yaylalarla birlikte gösterilmektedir.

Belirlenen yayla alanları için 2013 ile 2018 yılları arasındaki uydu görüntüleri Google Earth Pro (GEP) yazılımından elde edilmiştir. GEP, UA uydularından elde edilmiş değişik çözünürlükteki uydu görüntülerinin incelenebildiği bir bilgisayar yazılımdır. Çalışma alanı olarak belirlenen yaylalara ait geçmiş y1llara ait uydu görüntülerini de içermesi ve görüntü çözünürlüğünün bina ve yol ağının belirlenmesine imkân verecek düzeyde olması nedeniyle GEP tercih edilmiştir. Ayrıca günümüzde CBS yazılımları ile GEP verileri girdi olarak kullanılarak CBS işlem ve analizleri gerçekleştirilebilmektedir. 
CBS, konuma dayalı gözlemlerle elde edilen bilgilerin toplanmas1, depolanması, saklanmas1, işlenmesi ve kullanıcıya sunulması işlevlerini bir bütünlük içerisinde gerçekleştiren bir bilgi sistemidir. CBS sahip olduğu konumsal analiz yetenekleri sayesinde konum bilgisiyle alakalı her türlü uygulamada kendisine yer bulmaktadır. Özellikle, kentsel ve bölgesel planlama, çevrenin izlenmesi ve çevresel etki değerlendirmede, tarım, peyzaj, jeoloji, savunma, güvenlik, turizm vb. birçok uygulamalı meslek dallarında CBS önemli bir ortak kavram olarak kullanılmaktadır (Yomralığlu, 2000). Çalışma alanına ait toplanan veriler ArcMap yazılımında analiz edilerek sonuç ürünler elde edilmiştir. GEP'dan elde edilen uydu görüntüleri CBS yazılımında Universal Transverse Mercator (UTM) projeksiyon sistemi $37 \mathrm{~N}$ dilimi ve World Geodetic System (WGS) 1984 datumunda koordinatlandırılmıştır. Koordinatlandırma işleminin ardından yayla alanları için rektifiye edilmiş uydu görüntüleri üzerinden yol ve binalar sayısallaştırılarak (manüel olarak) vektör harita katmanları üretilmiştir. Son aşamada, yayla alanlarının zamansal değişimini ifade etmek için tablo ve haritalar hazırlanmıştır.

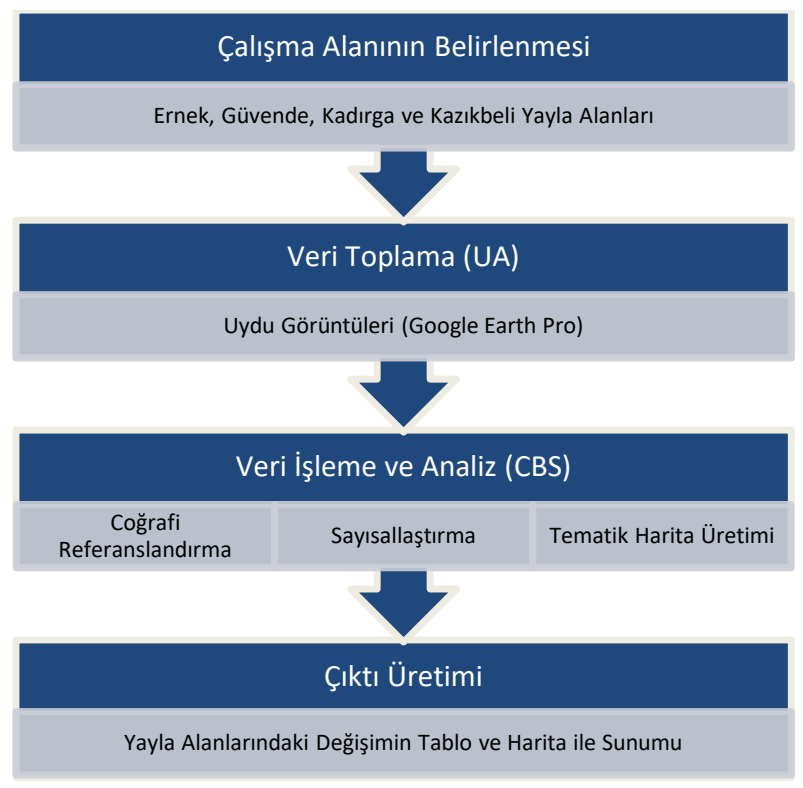

Şekil 2. Yayla alanlarındaki yapılaşma değişiminin belirlenmesinde işlem adımları

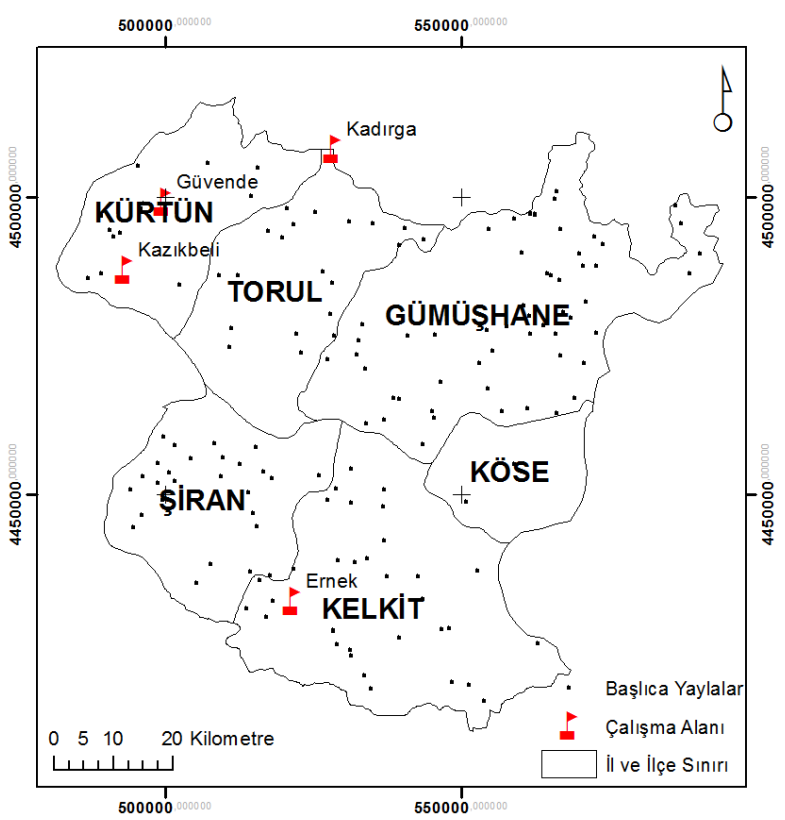

Şekil 3. Gümüşhane ilindeki başlica yaylalar ve çalışma alanı

\section{Bulgular}

Çalışma alanı olarak belirlenen dört yayla alanındaki yapılaşma değişimini belirlemek için kullanılan uydu görüntüleri Şekil 4'te, bu uydu görüntülerinden yararlanılarak CBS ortamında üretilen değişim haritaları Şekil 5'te gösterilmektedir. Uydu görüntülerinin tarihleri Ernek için 21.10.2013 ve 17.07.2018, Güvende için 01.10.2013 ve 25.08.2018, Kadırga için 12.09.2013 ve 17.05.2018, Kazıkbeli için 11.09.2013 ve 07.10.2018'dir. Şekil 5'te değişim haritaları üzerinde gösterilen bina sayısı ve yol uzunluğunda meydana gelen değişikliklerin sayısal değerleri Tablo 1'deki gibi hesaplanmıştır. 


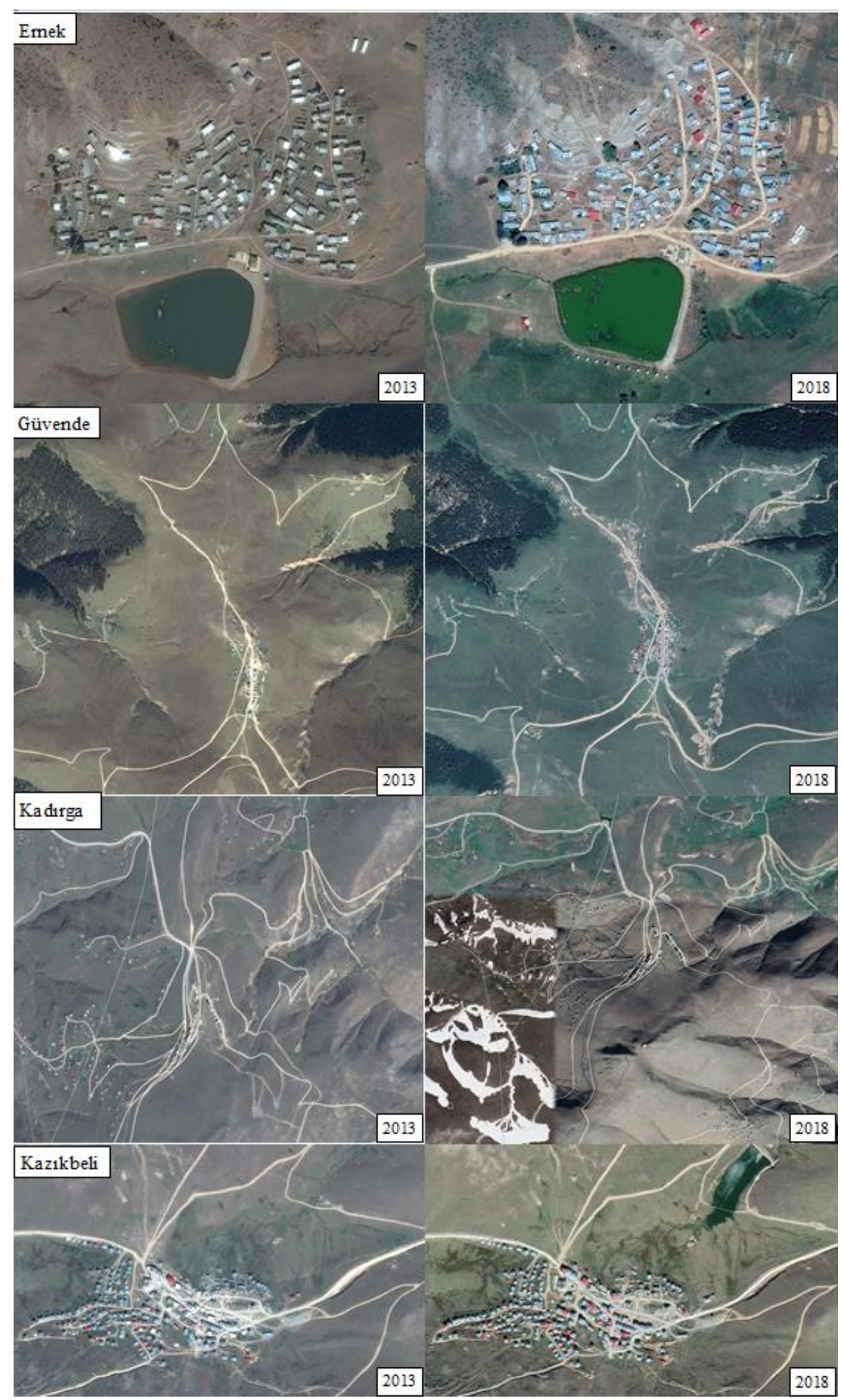

Şekil 4. Yayla alanlarına ait uydu görüntüleri (ölçeksiz)

Tablo 1 incelendiğinde tüm çalışma alanında bina sayıs1 2013 y1lında 661 olarak belirlenirken bu değerin 2018 yılında $142(\% 21.48)$ artışla 803 olduğu görülmektedir. Çalışma alanı geneli için 2013 y1lında toplam 44077.16 metre olarak hesaplanan yol uzunluğu 2018 y1lında 3059.25 metre (\%6.94) artışla 47136.41 metre olmuştur. Bina sayısında en büyük artış 84 bina ile Güvende yayla alanında en küçük artış ise 7 bina ile Kazıkbeli yayla alanındadır. 

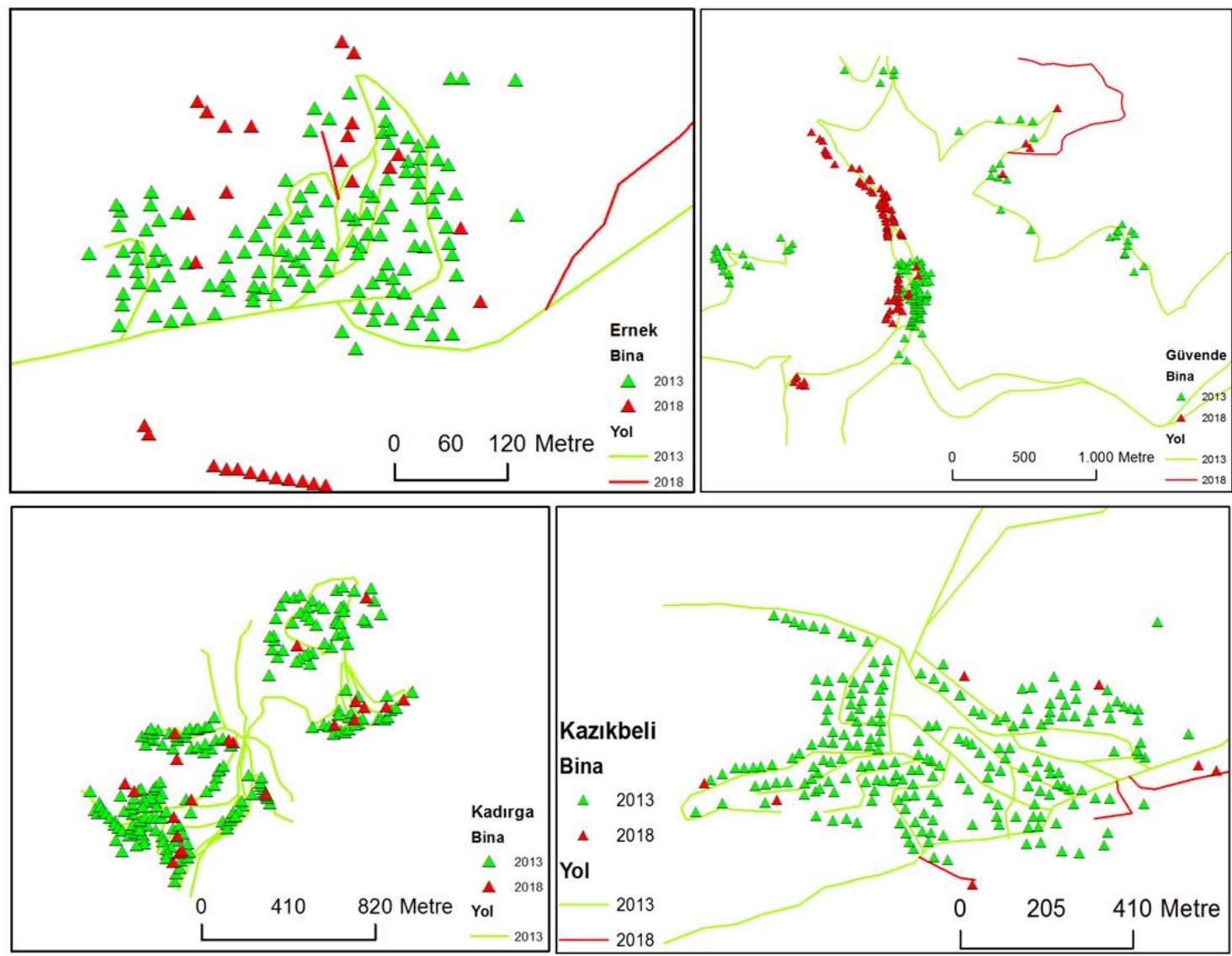

Şekil 5. Yayla alanı değişim haritaları

Tablo 1. Yayla alanlarında bina sayısı ve yol ağı uzunluğu değişimi

\begin{tabular}{lcccccccc}
\hline & \multicolumn{2}{c}{$\mathbf{2 0 1 3}$} & \multicolumn{2}{c}{$\mathbf{2 0 1 8}$} & \multicolumn{3}{c}{ Değişim (2013-2018) } \\
\hline Yayla Adı & $\begin{array}{c}\text { Bina } \\
\text { (adet) }\end{array}$ & Yol (m) & $\begin{array}{c}\text { Bina } \\
\text { (adet) }\end{array}$ & Yol (m) & $\begin{array}{c}\text { Bina } \\
\text { (adet) }\end{array}$ & $\begin{array}{c}\text { Bina } \\
(\boldsymbol{\%})\end{array}$ & Yol (m) & Yol (\%) \\
\hline Ernek & 134 & 2450.78 & 164 & 3023.09 & 30 & 22.39 & 572.31 & 23.35 \\
Güvende & 118 & 22014.39 & 202 & 23932.09 & 84 & 71.19 & 1917.7 & 8.71 \\
Kadırga & 196 & 10817.73 & 217 & 10817.73 & 21 & 10.71 & 0 & 0 \\
Kazıkbeli & 213 & 8794.26 & 220 & 9363.50 & 7 & 3.29 & 569.24 & 6.47 \\
Toplam & 661 & 44077.16 & 803 & 47136.41 & 142 & 21.48 & 3059.25 & 6.94 \\
\hline
\end{tabular}

\section{Sonuçlar}

Türkiye'de geçmişte geleneksel olarak hayvancılık faaliyetlerinin gerçekleştirildiği yayla arazilerinde, artan ulaşım olanakları ve turizm faaliyetlerinin etkisiyle günümüzde tatil ve turizm amaçlı, çoğunlukla yasadışı, bir arazi kullanımı ve yapılaşma söz konusudur. Bu çalışmada yayla alanlarındaki yapılaşma değişimi CBS ve UA verilerinin birlikte kullanımıyla incelenmiştir. Gümüşhane ilinde bulunan Ernek, Güvende, Kadırga ve Kazıkbeli isimli dört yayla alanında 2013 ile 2018 yılları arasındaki değişim haritalar üzerinde ve sayısal değerlerle belirlenmiştir. Buna göre, incelenen yayla alanlarında 2013 ile 2018 yılları arasında yapı sayısının \%21.48, yol ağının
\%6.94 artığı belirlenmiştir. $\mathrm{Bu}$ artışın temel sebeplerinin yayla alanlarına yönelik turizm faaliyetleri ve İmar Barışı düzenlemesinin olduğu değerlendirilmektedir. Yayla alanlarının sürdürülebilir kullanımı için koruma-kullanma dengesini gözeten bir arazi kullanım politikasına ve daha etkin bir denetim mekanizmasına ihtiyaç vardır. CBS ve UA verileri yayla alanlarındaki yapılaşma değişiminin izlenerek kontrol edilmesi çalışmalarına destek sağlamak için kullanılabilir.

\section{Kaynaklar}

AA-Anadolu Ajansı. (2020, 20 Mayıs). Erişim adresi https://www.aa.com.tr/tr/turkiye/imar-barisinda30-bini-askin-yapi-kayit-belgesi-iptaledildi/1735457. 
Akar, A. (2014). Mera ve yayla alanlarındaki değişimin tespiti ve yeni bir mera yönetim modeli yaklaşımı: Trabzon ili Akçaabat ilçesi örneği. Yüksek Lisans Tezi, Karadeniz Teknik Üniversitesi Fen Bilimleri Enstitüsü, Trabzon.

Arslanoğlu, U. (2019). The role of spatial designer in the prestigious housing projects: the case of Ankara. Yüksek Lisans Tezi, Orta Doğu Teknik Üniversitesi Şehir Planlama Bölümü. Ankara,

Bay, A. (2014). Uludă̆ yöresinde (Bursa) alternatif turizm türü olarak yayla turizmi. Yüksek Lisans Tezi, Çanakkale Onsekiz Mart Üniversitesi Sosyal Bilimler Enstitüsü, Çanakkale.

Başer, V. (2019). Yaylalardaki arazi kullanım değişiminin coğrafi bilgi sistemi ile analizi: Giresun örneği. Bitlis Eren Üniversitesi Fen Bilimleri Dergisi, 8(1), 167-175. https://doi.org/10.17798/bitlisfen.446264

Cengiz, S., Atmiş, E. ve Görmüş, S. (2019). The impact of economic growth oriented development policies on landscape changes in İstanbul province in Turkey. Land Use Policy, 87, 1-12. https://doi.org/10.1016/j.landusepol.2019.10408 6

Ceylan, M. (2014). Uzaktan algilama ve CBS ile yayla alanlarındaki değişimin izlenmesi: Gümüşhane örneği. Yüksek Lisans Tezi, Gümüşhane Üniversitesi Fen Bilimleri Enstitüsü, Gümüşhane.

Cin, M. (2019). İmar barışının yayla yerleşmeleri üzerindeki etkisinin uydu görüntüleri ile belirlenmesi: Giresun Karagöl Dağ1 örneği. Uluslararası Yaylacılık ve Yayla Kültürü Sempozyuтu, 26-28 Eylül, Giresun.

ÇŞB-Çevre ve Şehircilik Bakanlığı. (2018, 20 Mayıs). Erişim adresi https://webdosya.csb.gov.tr/db/imarbarisi/icerikl er/ brosur-20180603111057.pdf.

DOKAP-Doğu Karadeniz Projesi Bölge Kalkınma İdaresi Başkanlığı. (2020, 20 Mayıs). Erişim adresi https://www.dokap.gov.tr/projeler/yesilyol-projesi/1/Detay.

EEA, (2010). The European environment-state and outlook (2nd ed.). Copenhagen: European Environment Agency.

Gümüşhane Valiliği. (2017, 20 Mayıs). Erişim adresi http://gumushane.gov.tr/mera-ve-yaylalardakikacak-yapilasmayla-etkin-1mucadele-masayayatirildi.
Gürbüztürk, A. (2017). Social housing policy and the welfare regime in Turkey: a comparative perspective. Yüksek Lisans Tezi, Boğaziçi Üniversitesi Sosyal Bilimler Enstitüsü, İstanbul.

RG. (1989). Altıncı Beş Yıllık Kalkınma Planı (19901994). T.C. Resmi Gazete (20217, 6 Temmuz 1989).

RG. (1990). Turizmi Teşvik Kanunu. T.C. Resmi Gazete (20452, 5 Mart 1990).

RG. (1995). Yedinci Beş Yıllık Kalkınma Planı (19962000). T.C. Resmi Gazete (22354, 25 Temmuz 1995).

RG. (1998). Mera Kanunu. T.C. Resmi Gazete (23272, 28 Şubat 1998).

RG. (2007). Türkiye 2023 Turizm Stratejisi Eylem Planı. T.C. Resmi Gazete (26450, 2 Mart 2007).

Somuncu, M., Akpınar, N., Kurum, E., Kaya, N. Ç. ve Eceral, T. (2010). Gümüshane ili yaylalarındaki arazi kullanımı ve işlev değişiminin değerlendirilmesi: Kazıkbeli ve Alistire yaylaları örneği. Ankara Üniversitesi Çevrebilimleri Dergisi, 2(2), 107-127. https://doi.org/10.1501/Csaum_0000000031

Şakar, M. ve Kuruca, N. (2019). Yayla ve yaylacilık Bibliyografyası. Uluslararası Yaylacilık ve Yayla Kültürü Sempozyumu, 26-28 Eylül, Giresun.

TB-Turizm Bakanlığı. (2020, 20 Mayıs). Erişim adresi https://yigm.ktb.gov.tr/TR-11533/yayla-turizmmerkezleri.html.

Ting, L. and Williamson, I. (1999). Cadastral trends: a synthesis. The Australian Surveyor, 4 (1), 46-54. https://doi.org/10.1080/00050351.1999.1055877 2

Türk, M. (2019). Sinop Boyabat yayla yerleşimlerindeki kırsal mimari, koruma sorunlarl ve çözüm önerilerinin Alıç Yaylası örneğinde incelenmesi. Yüksek Lisans Tezi, Yıldız Teknik Üniversitesi Fen Bilimleri Enstitüsü, İstanbul.

Yomralığlu, T. (2000). Coğrafi Bilgi Sistemleri: Temel kavramlar ve uygulamalar (1.bask1). Trabzon: Seçil Ofset.

Yonca, Y. (2014). Kadirli'de yaylacılık faaliyetleri. Yüksek Lisans Tezi, Kahramanmaraş Sütçü İmam Üniversitesi Sosyal Bilimler Enstitüsü, Kahramanmaraş. 